\title{
Repensando la historia del Paraguay en tiempos de conmemoraciones
}

Las investigaciones sobre el Paraguay vienen logrando hacerse de un nicho en la academia argentina. Alrededor de veinte investigadoras/es de CONICET lo tienen como objeto de estudio, parcial o totalmente, abarcando las áreas de sociología, ciencias políticas, literatura, lingüística, antropología, geografía e historia. Si le añadimos becarias y becarios posdoctorales y doctorales más investigadoras/es de universidad nacionales, el número se duplica y más. De hecho, para poner sólo un ejemplo, el Taller "Paraguay desde las Ciencias Sociales" (organizado por el Grupos de Estudios Sociales sobre Paraguay, con sede en el IEALC de la UBA) viene desarrollándose ininterrumpidamente desde el año 2008, y la Revista Paraguay desde la Ciencias Sociales va por su número 9 y forma parte ya de doce indexadoras (DOAJ, Latindex, ERIHplus...). En la Universidad de Buenos Aires y en la Universidad Nacional de Formosa, Historia del Paraguay, existe como seminario optativo dentro de la carrera de Historia.

Lo mismo se aprecia en la región. En Brasil, donde las universidades fronterizas con el Paraguay mantienen programas de posgraduación centrados en lo regional, ocurre algo similar e investigadoras/es que tienen al Paraguay como objeto de estudio se han reunido en el grupo "Ñande - Rede de Pesquisadoras e Pesquisadores sobre o Paraguay". En Uruguay también se ha conformado un "Grupo de estudios sobre historia y cultura de Paraguay" con base en la UDELAR.

En el Paraguay los cambios vienen dándose más lentamente de lo deseado y esperado, pero con la creación del Programa Nacional de Incentivo a los Investigadores (PRONII, dentro del CONACyT) y del Programa Prociencia de Fomento a la Investigación Científica va incrementándose el caudal de investigaciones. Desgraciadamente las universidades, en lo que respecta a las áreas de las ciencias humanas y sociales, no se terminan de convertir en espacios académicos; de hecho, son las ONGs las beneficiarias más importantes del Programa Prociencia y no las Universidades.

Por otro lado, se ha conformado el Comité Paraguayo de Ciencias Históricas $(\mathrm{CPCH})$, miembro nacional del International Committee of Historical Sciences. A través de las múltiples actividades que organiza está poniendo al alcance del

Esta obra está sujeta a la Licencia Reconocimiento-NoComercial-CompartirIgual 4.0 Internacional de Creative Commons. http://creativecommons.org/licenses/by-nc-sa/4.0/ (cc) BY-NC-sa 
público nuevas miradas hacia la historia nacional fundamentalmente. Desde la Academia Paraguaya de la Historia, por su parte, se puso en circulación la Revista Paraguaya de Historia, con el sistema Open Journal System, para actualizar su prestigioso Anuario.

De las áreas que más se han desarrollado en esta última década, sin lugar a duda la historiografía ocupa el lugar más importante. Los trabajos pioneros de Liliana Brezzo, con su estudio introductorio del 2008 a las polémicas Báez-0'Leary de 1902-3 como referente obligado, marcaron una línea de investigación que fue seguida por muchos historiadores (Brezzo, 2008).

La edición de fuentes es otro de los ítems al que se la ha prestado una atención esmerada: memorias, diarios de viajes y epistolarios han sido publicados abriendo un nuevo campo de investigación y complementando la bibliografía existente. La digitalización también ha estado al orden del día y hoy contamos con casi todo el fondo del Archivo Nacional de Asunción digitalizado y una buena parte ya subido a la web (http://www.archivonacional.gov.py/). Por su parte, la Biblioteca Nacional de Paraguay tiene digitalizado todos los periódicos desde 1870 a 1900, un acerbo riquísimo del cual parte se encuentra en su página web (http://bibliotecanacional.gov.py/).

Desgraciadamente estos avances no se acompañan aún con un desarrollo académico. El grado de historia se dicta en tres universidades paraguayas, dos públicas y una privada, y sólo existe un posgrado, la "Maestría en Historia del Paraguay con énfasis en periodo independiente" que se dicta en la Universidad Nacional de Asunción. Existía antiguamente el doctorado en la UNA, pero se cerró hace más de una década.

Desde el año 2013, a través de le Ley 4995, existe una nueva legislación sobre la Educación Superior y se estableció la categoría de "profesor de tiempo completo", obligando a las universidades a poseer al menos el 30\% de su plantel docente con esta clase de profesores. Siendo tan pocas las carreras de historia, no hay docente que entre bajo esta categoría, aunque sí muchos enseñando en varios cursos por año sin tiempos pagos para la investigación. Es un extra.

A pesar de todo, la producción no cesa. En estos meses apareció la colección "Años que marcaron la historia del Paraguay", dirigida por Herib Caballero Campos, una serie de 10 libros monográficos editados por la editorial El Lector y distribuidos con el diario de mayor tirada del Paraguay, abc color. En esta colección, la mayoría de las y los autores pertenecen al $\mathrm{CPCH}$.

Si bien en estos años en Paraguay se conmemora los 150 años de la guerra contra la Triple Alianza, no se ha generado una renovada producción historiográfica sobre el particular. Sí se han reeditado obras clásicas como la de la Efraím Cardozo, Hace 100 años, o las memorias de Juan Crisóstomo Centurión, entre otras.

En marzo de 2015 se aprobó la Ley 5401 "Que declara "Sesquicentenario de la Epopeya Nacional", el lapso comprendido entre el 11 de noviembre de 2014 y el 1 de marzo de 2020". Cinco artículos, breve, pensada fundamentalmente para los encabezados de los documentos oficiales y para las denominaciones de las 


\section{Presentación Dossier}

promociones educativas. Ese mismo año, a través de otra ley (5529/15) se crea una "Comisión Nacional de Conmemoración del Sesquicentenario de la Epopeya Nacional" integrada por representantes de los distintos ministerios y organizaciones, como la Academia Paraguaya de la Historia. Sin embargo, en junio del 2018 se promulga otra Ley, la 6090, en que unifica las anteriores (a la par que las deroga) e introduce algunos cambios, comenzando por la temporalidad, ahora es: Que declara "Sesquicentenario de la Epopeya Nacional", el lapso comprendido entre el 12 de octubre de 2014 y el 22 de junio de 2026, y crea la "Comisión Nacional de Conmemoración del Sesquicentenario de la Epopeya Nacional: 1864 $1870 "$.

Hay cambio que son significativos. En la Ley del 2015 la Epopeya comenzaba con la toma del buque Marqués de Olinda y culminaba con la muerte del Mariscal Francisco Solano López; en la del 2018, se inicia con la invasión de Brasil al Uruguay y culmina con la desocupación de Asunción por las tropas aliadas. Se redefine, ciertamente, las causas y las consecuencias de la guerra. También se cambia la denominación "Guerra de 1870" por la de "Guerra contra la Triple Alianza". Quizá, lo más significativo sea la eliminación de uno de los cuatro objetivos propuestos en el 2015 para la Comisión: “animar el diálogo y la reflexión política en todos los ámbitos de la ciudadanía, en relación al pasado, presente y futuro de la sociedad nacional".

El cambio debe entenderse por la crisis que atravesó la Secretaría Nacional de Cultura a fines del 2016 (la Comisión había iniciado sus actividades el 16 de marzo de dicho año) donde hubo un cambio de Secretario Nacional de Cultura. Aunque había prometido continuar con los proyectos que estaban en ejecución, el más importante se descontinuó: el programa «Más Allá de la Guerra. Memoria, Reflexión y Cultura de la Paz».

Este programa había sido consensuado por los ministros de cultura de los países miembros del Mercosur a propuesta del Paraguay. El objetivo fundamental eral el "Promover un proceso de memoria y reflexión que habilite condiciones favorables y que múltiples perspectivas dialoguen para «ir más allá de la guerra», enlazando la contemporaneidad del pasado con la construcción del futuro". Se presentaba como un enfoque plural e innovador que por un lado articulaba la sociedad civil y el Estado y por el otro, se propendía a una articulación temática (educación, historia, economía, política...). Fruto de éste fue la realización un congreso importante sobre la temática con participación de investigadores de los cuatro países involucrados, que se llevó a cabo en octubre del 2015 en Asunción y salió publicado al año siguiente bajo el título "Más Allá de la Guerra: Aportes para el Debate Contemporáneo" (Asunción: Secretaria Nacional de Cultura, 2016). Este programa se interrumpió con el cambio de Secretarios adoptándose una mirada

más tradicional, centrada fundamentalmente en las batallas (sesquicentenario.gov.py).

Cuando en el 2011 se celebró el bicentenario de la independencia, desde el Estado mismo se destinó una importante suma de dinero, no sólo para los festejos en sí 
sino también para publicaciones. El Ministerio de Educación, por ejemplo, sacó una "Colección Bicentenario" en la cual se reeditaban una veintena de títulos clásicos y nuevos de la historiografía paraguaya. Se puede estar de acuerdo o no con la selección, pero fue destinada a la misma una suma de dinero generosa.

En el caso de la Guerra contra la Triple Alianza no ocurre lo mismo. Las causas pueden ser pensadas, aunque no comprobadas. Primeramente, que abarca un período más largo y si se lleva hasta el 2026, mucho más. También, que afecta a varias administraciones, comenzó con la presidencia de Horacio Cartes, continúa con la Mario Abdo Benítez y culminará con la siguiente. Incluso, los cambios al mismo interior de la Secretaría Nacional de Cultura tampoco ayudaron, y el cambio del contexto político regional, menos. No puede dejar de señalarse que, aún, el tema de la guerra es una quaestio disputata no sólo entre historiadores e intelectuales sino en la comunidad misma. ${ }^{1}$

La dictadura de Alfredo Stroessner (1954-1989) hizo de la historia su caballito de batalla cultural y, designando a Juan E. O'Leary como el historiador oficial, clausuró la discusión historiográfica (Brezzo, 2008; Capdevilla, 2010). No deja de ser sintomático que la última obra historiográfica escrita en el Paraguay sobre la Guerra contra la Triple Alianza sea la de Efraím Cardozo, Hace cien años, publicada precisamente hace cincuenta años (Cardozo, 1967-1982). Ni tampoco fue pensada ésta como tal, sino que eran artículos periodísticos que día tras día aparecían en el diario La Tribuna. Compuesta de 13 tomos, el último apareció en 1983, una década después que al autor haya fallecido.

Esta situación genera un resultado doble: por un lado, que se siga insistiendo en reescribir una historia tradicional de la guerra, heroica, con la categoría de nación como base de todo análisis e interpretación (la nueva Comisión del Sesquicentenario es una muestra cabal); y por el otro, que la nueva camada de historiadoras e historiadores huyan de esos temas para concentrarse en otras áreas y en otros períodos (el libro editado por el $\mathrm{CPCH}$, Historia del Paraguay. Nuevas perspectivas, es otro botón de muestra) (Telesca y Gómez Florentín, 2018). Este dossier que presentamos se propone aportar a una profundización historiográfica. Los artículos que forman parte del mismo abordan cuestiones relacionadas sí con la Guerra contra la Triple Alianza, aunque ninguno de ellos la aborda de manera directa.

Magdalena López contribuye con una reflexión necesaria: ¿de qué hablamos cuando hablamos del Estado lopista? Solemos referirnos a él con la caracterización de 'Estado moderno' o que con Carlos Antonio López se produce la modernización del Estado en Paraguay. Pareciera que damos por sabido qué entendemos por 'Estado' y por 'moderno', al mismo tiempo que damos por supuesto que el Estado francista no era moderno. Demasiados supuestos.

\footnotetext{
${ }^{1}$ En el mes de mayo se iría a presentar una obra de teatro "Las locuras del Mariscal". Ante la infinidad de críticas y amenazas recibidas a través de las redes sociales, la producción de la misma resolvió postergar la presentación.
} 


\section{Presentación Dossier}

López parte de reseñar las obras referidas a la conformación del Estado-nación en América Latina para ir concentrándose en la bibliografía referente al Paraguay. Para ir desentrañando la cuestión sobre el Estado nacional en la época de los López hace uso de la obra de Oscar Oszlak y de sus criterios de estatidad.

La autora concluye, al margen de cómo sean consideradas las políticas lopistas, señalando la existencia de suficientes rasgos de un Estado nacional en el período de 1840-1870.

Este artículo, que se presenta como pórtico dialoga con dos temas que serán centrales para comprender la conformación del Estado moderno en Paraguay: la Iglesia y la posesión de la tierra.

El Dr. Francia había suprimido los conventos, cerrado el Seminario y prohibido la entrada a nuevos eclesiásticos. Los sacerdotes que había se iban envejeciendo, quien no muriendo. Finalmente, el obispo falleció, dos años antes que el Dr. Francia.

Carlos Antonio López, ante esta situación de precariedad y con la posibilidad/necesidad de comenzar casi de cero el armado eclesiástico, resolvió hacer de la Iglesia y de sus ministros los capilares para la difusión de su concepción de Estado, de patria, de nación. Volvió a abrir una Academia Literaria, luego Seminario; renovó y reedificó un sin número de templos; estableció relaciones con el papado para el nombramiento de un nuevo obispo y se generó así una nueva generación de sacerdotes-ciudadanos, los que tendrían una actuación especial en la Guerra contra la Triple Alianza. Más que la militarización, más que la educación, fue la institución eclesial la elegida para que en guaraní toda la población se enterase de las nuevas buenas estatales.

El control del territorio y de la posesión de la tierra fue también una herramienta de control estatal. López continuó la política de arrendamiento de tierras que provenía ya de tiempos coloniales y que con el Dr. Francia se afianzó aún más. Según las recientes investigaciones, la mayoría de la población vivía y producía en tierras arrendadas al Estado. Al mismo tiempo, los yerbales y los bosques de maderas fueron declarados de usufructo y explotación estatal, lo que impactó poderosamente en las arcas del Estado. Hay una disputa sobre si el control de la tierra implicaba un control de la población, lo que no se cuestiona es la importancia del control de los yerbales para el crecimiento económico experimentado tras el reconocimiento de la independencia por parte de la Confederación Argentina en 1852.

De 1852 a 1864 el Paraguay experimentó un crecimiento económico más que importante, crecimiento controlado por el Estado y siendo éste el principal beneficiario. Una década duró este viento a favor, luego pareció que ya era demasiado independencia para los países vecinos. La guerra se desató en 1864 sin prever de ningún lado las consecuencias ni la duración de la misma.

Victoria Baratta, desde un punto de visto discursivo, viene llamando la atención sobre la centralidad de la Guerra contra la Triple Alianza en la constitución del Estado nacional en Argentina. Se suele contextualizar geográficamente el apoyo a 
la guerra en la prensa porteña y su rechazo en la del interior, reproduciendo y trasladando la disputa unitario-federal a la contienda. Baratta muestra la extensión del apoyo a la continuación de la guerra y nos explica el por qué del mismo, como también las razones de su rechazo.

Finalmente, el texto de Liliana Brezzo nos sumerge nuevamente en la cocina de la producción historiográfica, nos adentra en la intimidad de quien fuera el escritor más importante del Paraguay sobre este período hasta épocas recientes: Juan Emiliano O'Leary. Brezzo viene trabajando sobre el corpus que representan los escritos privados de O'Leary (diario, correspondencias, memorias). En esta ocasión, la autora se centra en la producción de O'Leary sobre la guerra y en particular en las redes que iba tejiendo con intelectuales regionales, de Uruguay, de Brasil, de Argentina. Cuando nos referimos al revisionismo, local y regional, la figura de 0'Leary se presenta como nuclear.

Profundizar en la construcción de Estado en Paraguay a la par de los relatos historiográficos aún vigentes nos permiten no sólo adentrarnos en una historia particular sino comenzar a ampliar el círculo y asumir a la región como un todo, con sus dispares respuestas a problemas comunes.

Ignacio Telesca

Instituto de Investigaciones sobre Lenguaje, Sociedad y Territorio

Universidad Nacional de Formosa, Consejo Nacional de Investigaciones Científicas y Técnicas (Argentina) itelesca@conicet.gov.ar

\section{Bibliografía}

Brezzo, L. (2008). "En el mundo de Ariadna y Penélope: hilos, tejidos y urdimbre del nacimiento de la historia en Paraguay". En Polémica sobre la Historia del Paraguay. Asunción: Tiempo de Historia.

Capdevila, L (2010) Una guerra total. Paraguay, 1864-1870. Ensayo de historia del tiempo presente. Buenos Aires: SB.

Cardozo, E. (1967-1982). Hace cien años: crónicas de la Guerra de 1864-1870. Publicadas en "La Tribuna" de Asunción en el centenario de la epopeya nacional. 13 tomos. Asunción: Ed. EMASA.

Telesca, I. y Gómez Florentín, C. (eds.) (2018). Historia del Paraguay. Nuevas Perspectivas. Asunción: CPCH-Servilibro. 